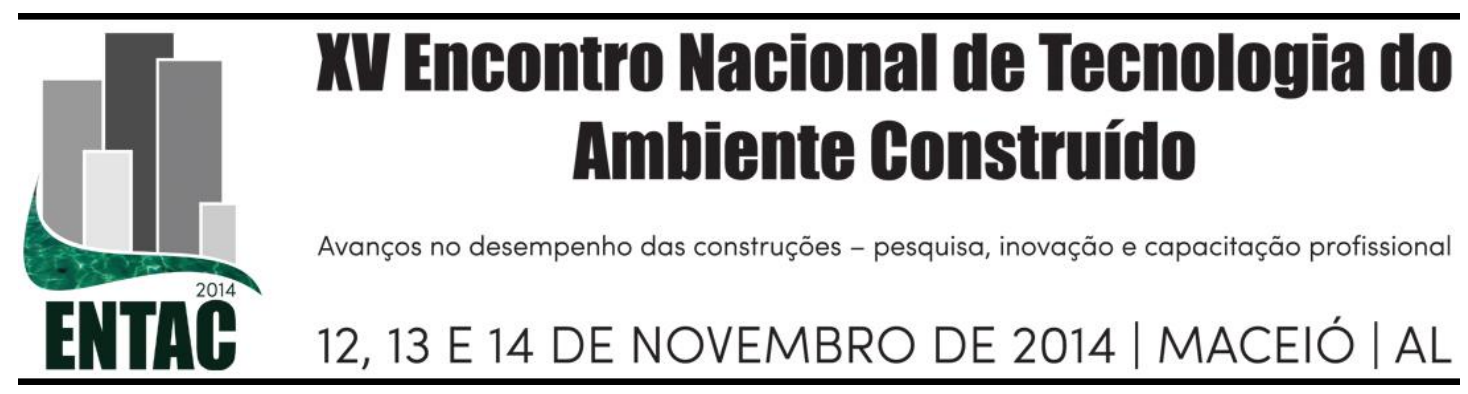

\title{
ANÁLISE DO PROJETO PADRÃO DE ESCOLA TÉCNICA DO MEC SOB DIFERENTES INCIDÊNCIAS DE VENTO
}

LAMENHA, Melyna (1); BATISTA, Juliana (2); BITTENCOURT, Leonardo (3)

(1) UFAL, e-mail: melynalamenha@gmail.com (2)UFAL, e-mail: juliana82arq@gmail.com, (3) UFAL, e-mail: 1sb54@ hotmail.com

\begin{abstract}
RESUMO
Para o melhor aproveitamento do recurso da ventilação natural, ao projetar um edifício é preciso orientálo de maneira adequada em relação aos ventos dominantes do local em que a edificação será implantada. No entanto, em fevereiro de 2011, foi apresentado pelo Ministério da Educação - MEC, um projeto de arquitetura padrão para escolas técnicas do programa Brasil Profissionalizado, visando sua implantação em todo o Brasil. O objetivo principal do presente trabalho é analisar o comportamento da ventilação natural externa nesse projeto padrão de escola técnica do MEC, avaliando-se a distribuição de pressões nas fachadas dos diversos blocos que compõem a escola, considerando oito ângulos de incidência do vento. O estudo foi realizado por meio de simulações no programa de Mecânica Computacional dos Fluidos (CHAM, 2005). Foram simulados oito modelos, considerando o edifício submetido a oito incidências de vento distintas. Os resultados mostram diferenças significativas da distribuição das pressões nas superfícies externas à edificação, dependendo do ângulo de incidência do vento. Das oito incidências analisadas, as incidências a $45^{\circ}$ apresentam maior diferença de pressão entre fachadas opostas do edifício. Com incidência de $90^{\circ}$, nos ambientes com fachadas paralelas à direção do vento, a movimentação do ar interno foi praticamente nula. A ventilação natural é uma das estratégias bioclimáticas que podem ser controladas por meio de decisões projetuais simples, como a localização adequada das aberturas, favorecendo o conforto térmico e a redução do consumo de energia elétrica em edifícios escolares. O uso de simulação computacional torna-se uma ferramenta auxiliar na arquitetura, permitindo a análise prévia de fatores que podem interferir na qualidade dos projetos.
\end{abstract}

Palavras-chave: Edifícios educacionais, ventilação natural, simulação computacional.

\begin{abstract}
To achieve proper natural ventilation performance in a building, designers must locate it with adequate orientation regarding the prevailing winds directions. Nevertheless, in February 2011, the Brazilian Ministry of Education, as part of the Professionalized Brazil Program, launched a standard architectural project for new Technical School buildings, to be constructed throughout Brazil. The main objective of this paper is to analyze the natural ventilation performance of this standard project. It aims, also, to evaluate the distribution of external pressures, as a result of eight different wind incidence angles. The study was conducted by computer simulations in a CFD program (CHAM, 2005). Eight models were simulated, considering eight different wind incidences. Results show significant differences in pressure distribution on the building envelope, depending on the wind angle incidence. Among the eight examined incidences, when blowing at $45^{\circ}$ in relation to facades, greater pressure differences were obtained regarding opposite facades. With $90^{\circ}$ incidence, parts of the building envelope which were parallels to the wind direction, generated insignificant pressure differences suggesting a poor indoor air movement. Natural ventilation is one of bioclimatic strategies that can be controlled by simple project decisions, such as windows location, important step to improve thermal comfort and reduce energy consumption in school buildings. The use of CFD simulation becomes an auxiliary tool in architecture, allowing preliminary analysis of factors that can affect the quality of projects.
\end{abstract}

Keywords: Educational buildings, natural ventilation, computational simulation. 


\section{INTRODUÇÃO}

Edifícios bioclimáticos adaptam-se às condições dos locais onde estão implantados. Fazem uso dos recursos naturais disponíveis e contribuem para a redução de impactos ambientais, bem como para a redução do consumo de energia elétrica.

É recomendável o uso de estratégias bioclimáticas para a elaboração de edifícios eficientes energeticamente:

"A racionalização do uso da energia apresenta estreitos laços com a adequação da arquitetura ao clima, evitando ou reduzindo os sistemas de condicionamento artificial de ar, quer com a finalidade de refrigerar, quer com a de aquecer os ambientes ." (FROTA; SCHIFFER, 2003, p.16).

O Brasil apresenta variações significativas no que diz respeito ao clima. Cada zona bioclimática exige um conjunto diferente de estratégias para a promoção do conforto térmico nos edifícios.

Como afirmam Lamberts, Dutra e Pereira (2004), "o repertório do arquiteto deve ser mais amplo, permitindo que as especificidades de cada local aflorem como condicionantes a serem respeitados em uma linguagem arquitetônica adequada".

Em fevereiro de 2011, foi disponibilizado pelo Ministério da Educação - MEC, uma atualização do projeto de arquitetura executivo padrão e caderno de especificações técnicas da escola do programa Brasil Profissionalizado, visando sua implantação em todo o Brasil. A implantação de um mesmo projeto em uma região com condições climáticas totalmente distintas, como o território brasileiro, pode resultar em problemas de desempenho térmico e energético do edifício, devido ao mau uso dos recursos naturais disponíveis.

Dependendo do clima, a ventilação natural torna-se uma estratégia eficaz para a obtenção de conforto térmico e a eficiência energética nas edificações, inclusive estabelecimentos de ensino. Para o melhor aproveitamento da ventilação natural, devese orientar o edifício de maneira adequada em relação aos ventos dominantes do local em que a edificação será implantada.

A energia cinética do vento é transformada em energia potencial (pressão) contra obstáculos, como os edifícios, impulsionando a ventilação (ALLARD; GHIAUS; MANSOURI, 2003, p.12). Portanto, quanto maior a diferença de pressão do vento entre as aberturas de entrada e saída maior a possibilidade de movimentação do ar no interior do edifício.

O objetivo deste trabalho é analisar o comportamento da ventilação natural do projeto padrão de escola técnica do MEC, quanto à distribuição de pressões nas faces externas do edifício, em função de oito possíveis incidências do vento (perpendiculares e oblíquas às fachadas) por meio de simulações computacionais que utilizam no programa PHOENICS VR 3.6.1 (CHAM, 2005).

\section{MÉTODO}

\subsection{Caracterização do objeto de estudo}

A edificação analisada é o projeto padrão de escola técnica apresentado pelo Ministério da Educação - MEC, em fevereiro de 2011, visando sua implantação em todo o Brasil, como parte do programa Brasil Profissionalizado (Figura 1). 
Figura 1 - Maquete do projeto padrão de escola técnica do MEC

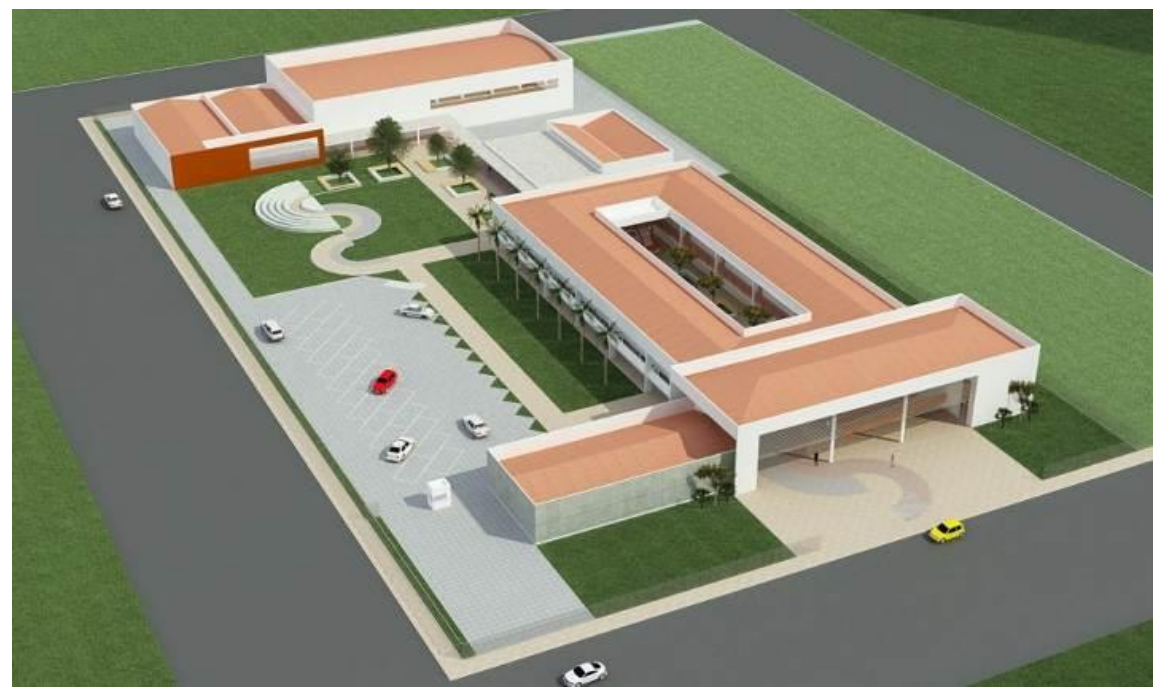

Fonte: MEC (2011)

O projeto é formado por um conjunto de blocos, ocupando um terreno com área de $12.004,17 \mathrm{~m}^{2}$. Dentre os blocos tem-se: a) auditório, b) biblioteca, c) laboratórios e salas de aula, d) refeitório, e) laboratórios especiais e f) quadra poliesportiva, como mostra a Figura 2. Como o projeto não possui terreno específico para implantação, não há indicação do norte nas plantas disponibilizadas.

Figura 2 - Planta Baixa do projeto padrão de escola técnica do MEC

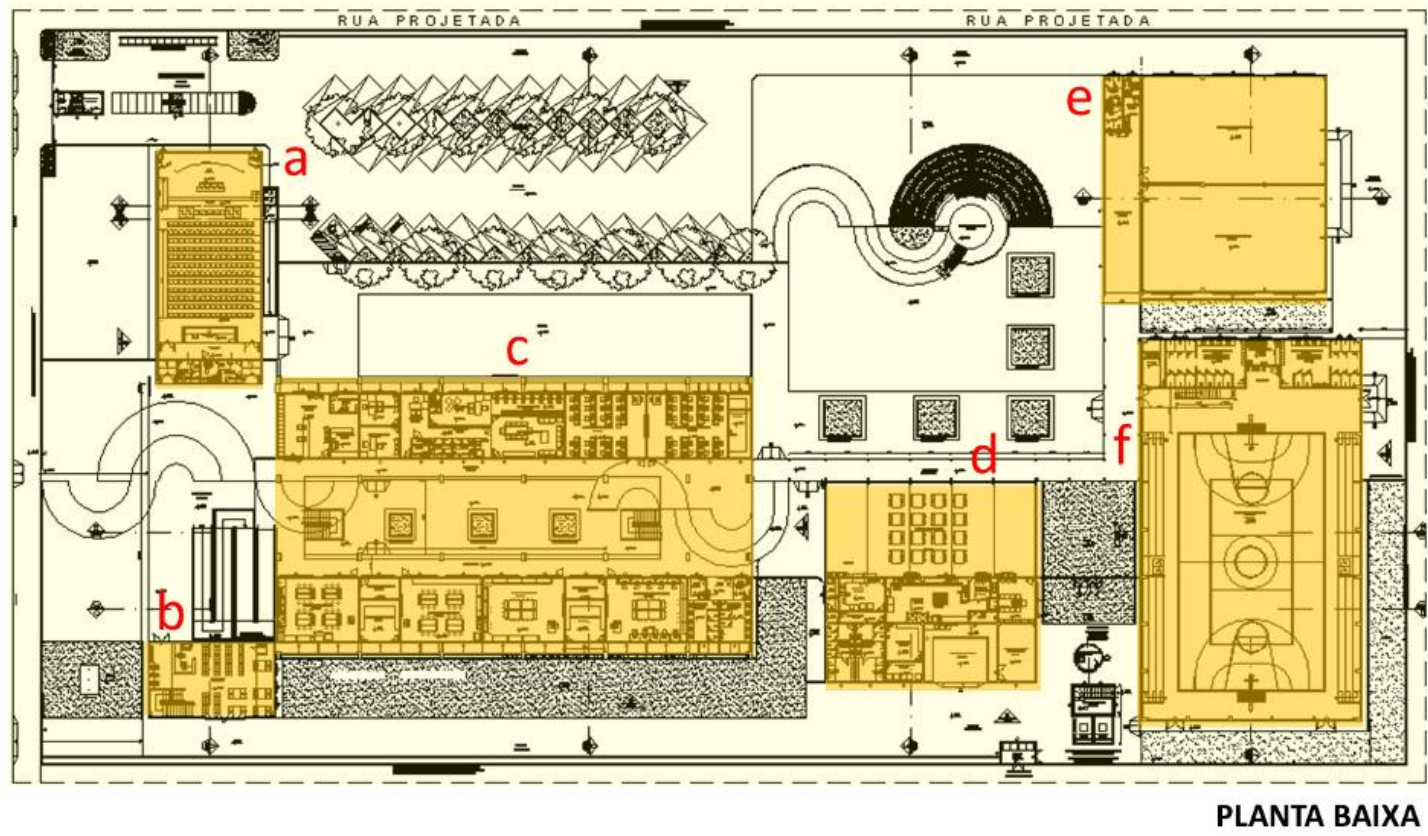

Fonte: Adaptado, MEC (2011)

O bloco de laboratórios e salas de aula contém a maior parte dos ambientes de ensino, sendo indispensável o seu posicionamento adequado, em relação aos ventos dominantes. Dessa forma, pode-se promover o conforto térmico, por meio da ventilação natural, assim como pela adequada proteção solar das aberturas. 


\subsection{Simulação computacional}

O estudo foi realizado por meio de simulações no programa de Mecânica Computacional dos Fluidos, PHOENICS VR 3.6.1 (CHAM, 2005).

O programa é uma das ferramentas mais avançadas na investigação do comportamento da ventilação natural (CHOW apud CÂNDIDO, 2006). Os resultados fornecidos pelo programa computacional, em forma de gráfico, fornecem dados de direção, sentido, velocidade e pressão do vento externo e interno à edificação. Os gráficos podem ser apresentados em forma de vetores e/ ou campos de cores.

O processo de simulação inclui três etapas: a construção e configuração do modelo de simulação; a realização dos cálculos e a visualização dos resultados.

Para a configuração do modelo, deve ser especificada a velocidade média o vento para a simulação. Foram consideradas as velocidades médias anuais de oito cidades com características climáticas distintas (Quadro 1).

\section{Quadro 1 - Cidades escolhidas e velocidade média adotada}

\begin{tabular}{|c|c|c|}
\hline Cidade & Zona Bioclimática & Velocidade média anual \\
\hline Brasília - DF & 4 & 2,45 \\
\hline Campo grande - MS & 6 & 3,45 \\
\hline Curitiba - PR & 1 & 2,18 \\
\hline Florianópolis - SC & 3 & 2,43 \\
\hline Maceió - AL & 8 & 2,73 \\
\hline Manaus - AM & 8 & 1,40 \\
\hline Petrolina & 7 & 3,08 \\
\hline Rio de Janeiro - RJ & 8 & 1,35 \\
\hline Velocidade média adotada & 2,45 \\
\hline
\end{tabular}

Fonte: Adaptado, LABEEE (2014)

Observou-se uma semelhança entre os dados de quatro cidades, calculando-se um valor médio de velocidade do vento de $2,45 \mathrm{~m} / \mathrm{s}$. Esse valor foi corrigido por meio da Equação 1 , considerando o gradiente da velocidade do vento e os coeficientes de rugosidade do terreno, que caracterizam o entorno como área suburbana (ver Quadro 2), já que os centros de cidade geralmente possuem poucas áreas livres para a implantação de grandes estabelecimentos de ensino públicos.

$$
V=k \cdot z^{a} \cdot V_{m}
$$

onde, $\mathrm{V}=$ velocidade média do vento na altura da abertura de entrada do $\mathrm{ar}(\mathrm{m} / \mathrm{s})$;

$\mathrm{V}_{\mathrm{m}} \quad=$ velocidade média do vento, medida na estação meteorológica a uma altura padrão de $10 \mathrm{~m}(\mathrm{~m} / \mathrm{s})$;

$\mathrm{z}=$ altura da abertura de entrada do vento $(\mathrm{m})$;

$\mathrm{k}, \mathrm{a}=$ coeficientes de acordo com a rugosidade do entorno. 
Quadro 2 - Coeficientes de rugosidade do terreno

\begin{tabular}{|c|c|c|}
\hline Terreno & $\mathbf{k}$ & $\mathbf{a}$ \\
\hline Área aberta plana & 0,68 & 0,17 \\
\hline Campo com obstáculos esparsos & 0,52 & 0,2 \\
\hline Área suburbana & 0,35 & 0,25 \\
\hline Centro de cidade & 0,21 & 0,33 \\
\hline
\end{tabular}

Fonte: Adaptado, Jakcman apud Bittencourt; Cândido (2008)

Foram criados oito modelos tridimensionais para simulação com base no projeto arquitetônico da edificação estudada. Cada modelo foi simulado sob uma incidência de vento distinta. Foram consideradas as oito orientações, sendo quatro incidências de vento perpendiculares e quatro oblíquas às fachadas, conforme mostra a Figura 3.

\section{Figura 3 - Incidências de vento simuladas}

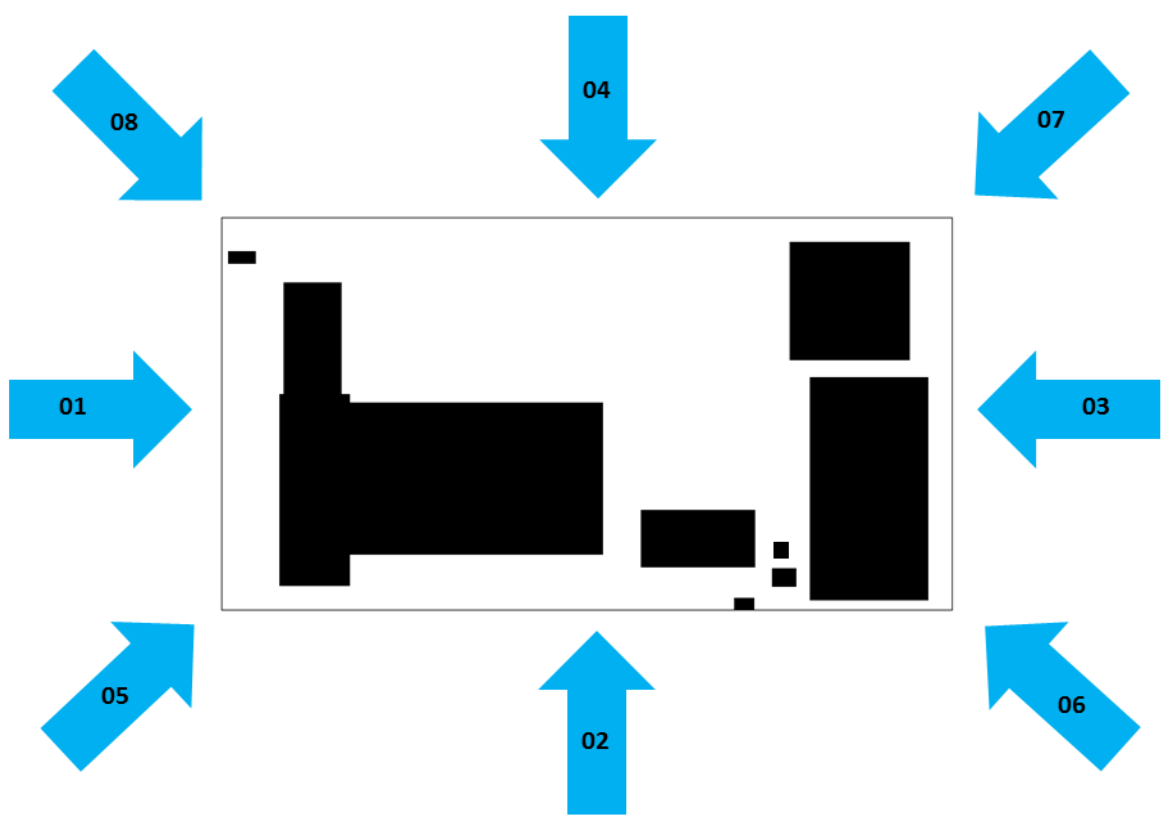

Fonte: Adaptado, MEC (2011)

Para a análise foram considerados planos horizontais nas alturas do centro das janelas: no pavimento térreo a $1,50 \mathrm{~m}$ e no $1^{\circ}$ pavimento a $5,40 \mathrm{~m}$.

Após a simulação dos modelos descritos, foi feita a análise comparativa das pressões externas aos blocos da edificação estudada, conforme os ventos incidentes. A presente análise se destina às condições do vento externo à edificação. Portanto, foram identificadas as regiões com maiores diferenças de pressão, o que indica a possibilidade de maior movimentação de ar. Tais informações permitem identificar quais as melhores condições para o posicionamento de abeturas localizadas a barlavento ou sotavento.

Por se tratar de um estudo preliminar das pressões externas à edificação, considerou-se apenas a disposição dos volumes que compõem a escola sem áreas de abertura. 


\section{ANÁLISE DE RESULTADOS}

Dentre as oito incidências analisadas, foi possível observar variações significativas da distribuição das pressões em torno da edificação. Ao lado dos gráficos observa-se a escala de pressões obtida nas simulações, onde os valores estão fixados de $-3,00 \mathrm{~Pa}$ a $3,00 \mathrm{~Pa}$ e cada cor representa um valor correspondente às pressões do vento.

Duas incidências a $45^{\circ}$, correspondentes às orientações 06 e 08 (vide Figura 3), apresentaram maior diferença de pressão entre fachadas opostas, o que possibilita uma distribuição mais uniforme do fluxo de vento no complexo edificado (Quadros 3 e 4).

\section{Quadro 3 - Orientação 06, incidência do vento a $45^{\circ}$}

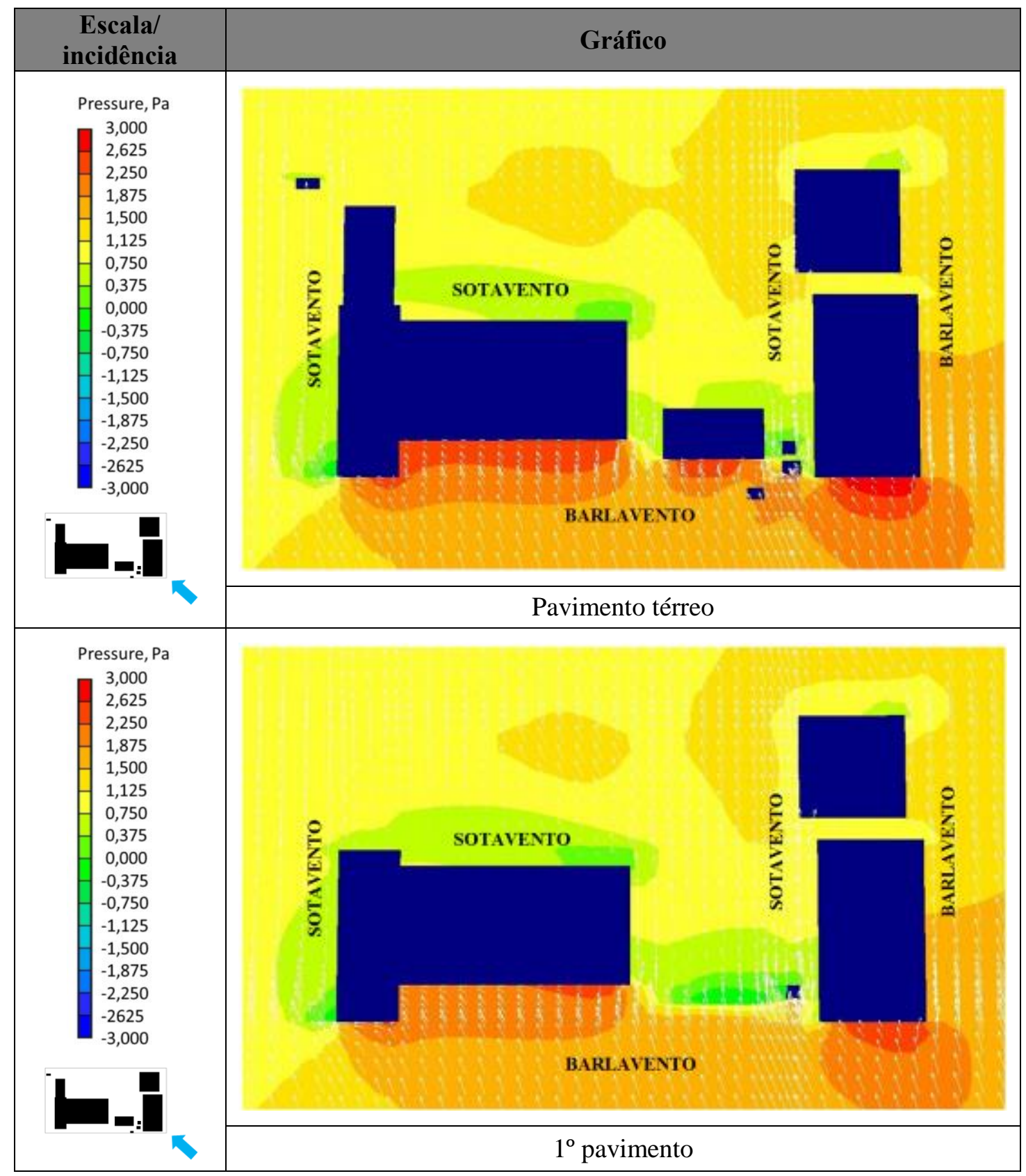

Fonte: Adaptado, CHAM (2005) 


\section{Quadro 4 - Orientação 08, incidência do vento a $45^{\circ}$}

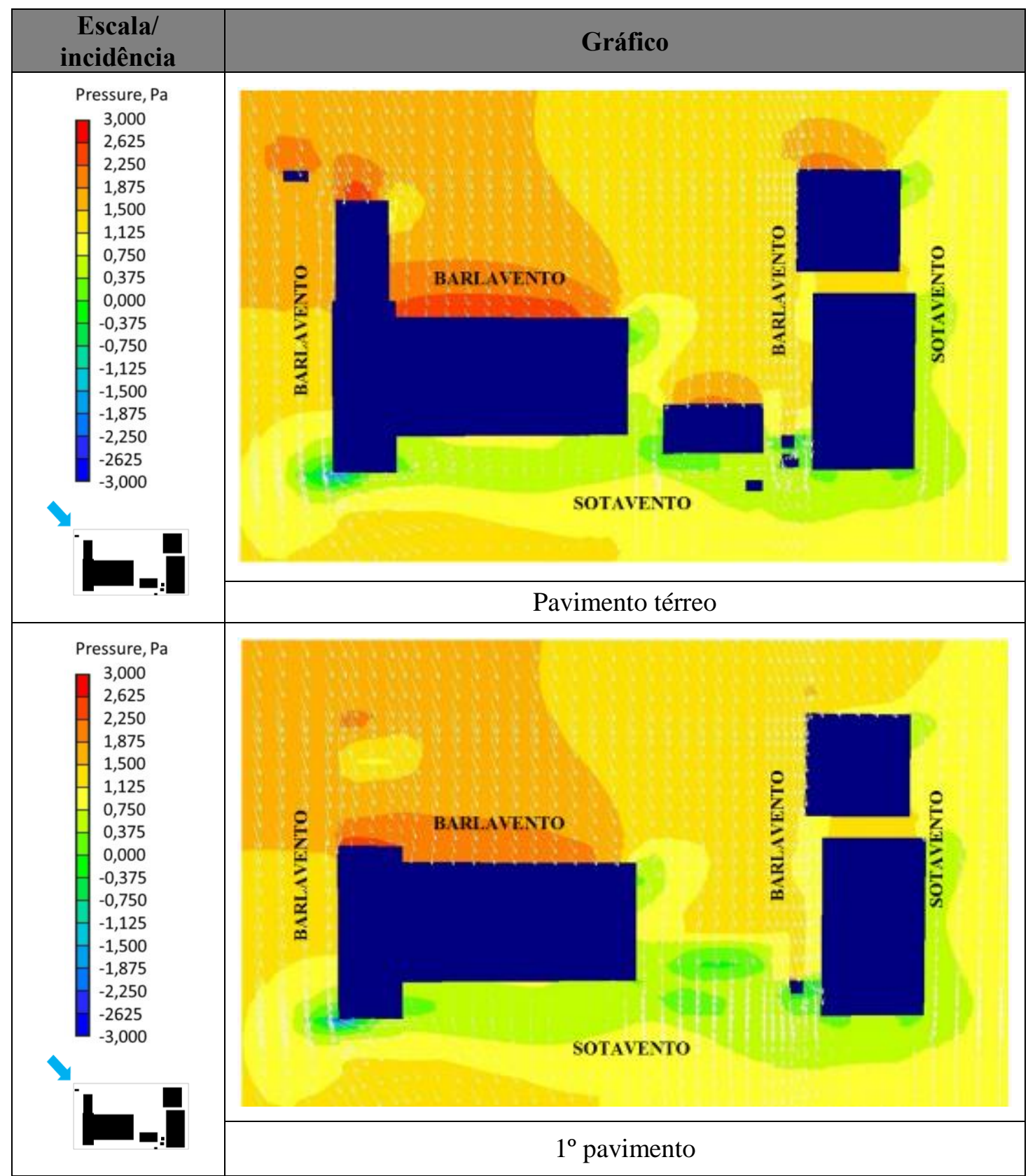

Fonte: Adaptado, CHAM (2005)

Para cada orientação, comparando-se o pavimento térreo e o $1^{\circ}$ pavimento, as pressões mostraram-se semelhantes. As cores amarelo, laranja e vermelho indicam pressões maiores (barlavento), enquanto que as cores verde e azul, mostram pressões mais baixas (sotavento).

No bloco de laboratórios e salas de aula, área onde está concentrada a maior parte dos ambientes de ensino (vide Figura 2), as aberturas localizam-se nas fachadas mais extensas, posição ideal para permitir a entrada da ventilação por meio das diferenças de pressão observadas nas orientações 06 (Quadro 3) e 08 (Quadro 4). 
A disposição dos blocos no terreno, em forma de "U", também contribui para o bom desempenho do edifício quanto ao aproveitamento da ventilação natural, sob incidências a $45^{\circ}$, devido à implantação dos blocos.

As demais orientações analisadas, principalmente as de incidência a $90^{\circ}$ (orientações 01 a 04), apresentaram diferenças de pressão menores do que as orientações 06 e 08 . A orientação 03 (Quadro 5) apresentou as menores diferenças de pressão em torno do projeto. Nas partes da edificação paralelas à direção do vento, a possibilidade de movimentação do ar interno foi reduzida, apresentando pressões semelhantes em fachadas opostas.

\section{Quadro 5 - Orientação 03, incidência do vento a $90^{\circ}$}

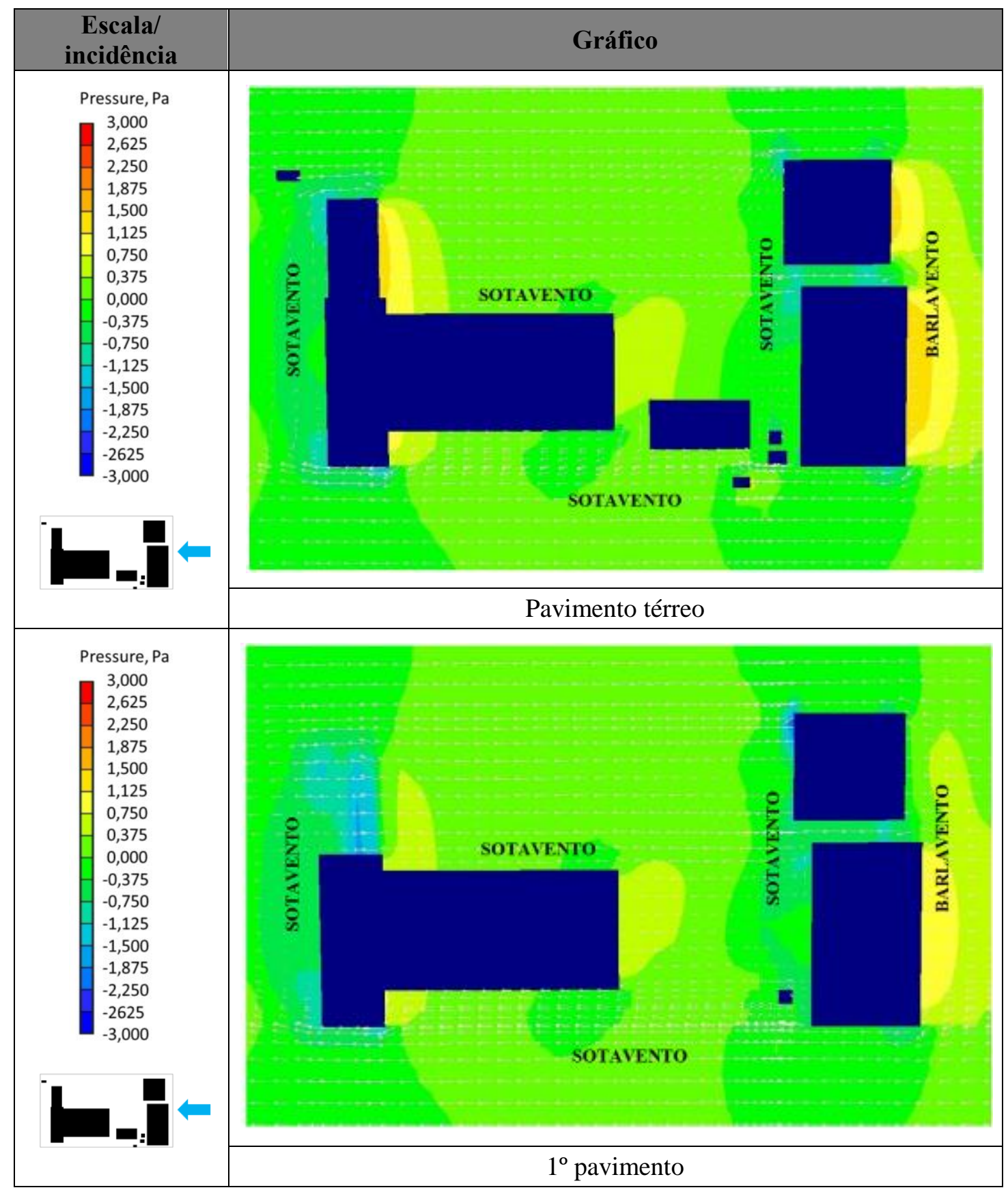

Fonte: Adaptado, CHAM (2005) 
Os resultados mostram grandes diferenças da distribuição das pressões nas superfícies externas à edificação, dependendo do ângulo de incidência do vento.

É possível que o projeto padrão de escola técnica do MEC, apresente melhor desempenho quanto à ventilação natural, quando implantado de maneira que os ventos dominantes incidam à $45^{\circ}$, conforme os resultados demonstrados nas orientações $06 \mathrm{e}$ 08 (Quadros 3 e 4) desta análise.

Os gráficos das cinco orientações restantes estão resumidos no Quadro 6 a seguir.

\section{Quadro 6 - Resumo dos resultados, orientações 01, 02, 04, 05 e 07}

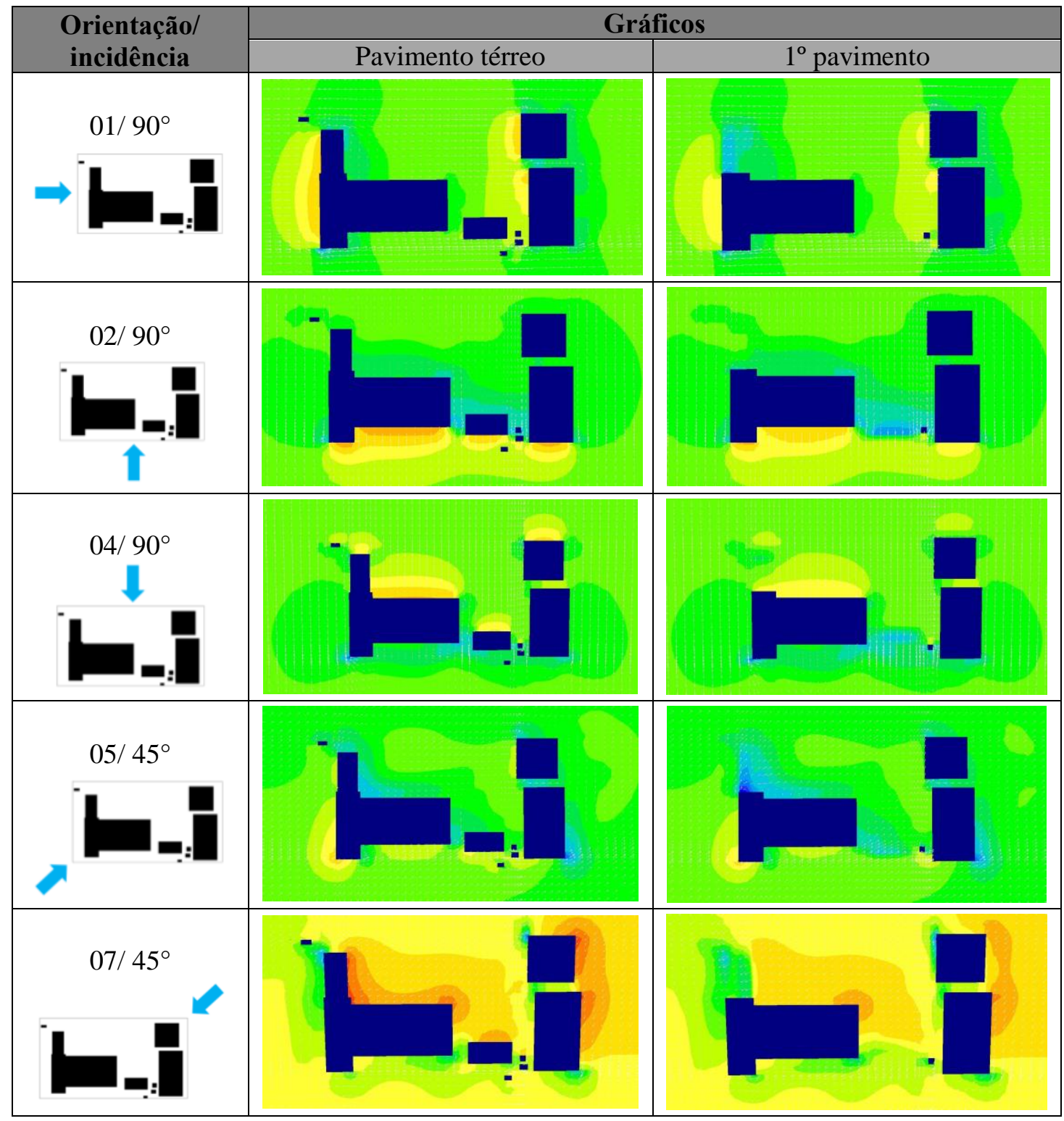

Fonte: Adaptado, CHAM (2005)

\section{CONCLUSÕES}

Este trabalho analisou o comportamento da ventilação natural externa do projeto padrão de escola técnica do MEC, destacando-se os resultados referentes a três possíveis incidências de ventos. 
Os resultados demonstram a necessidade de orientar o projeto de maneira adequada aos ventos dominantes locais, para que ele apresente um bom desempenho nesse aspecto.

Nos diversos climas existentes no Brasil, a ventilação natural é uma solução aplicável, desde que sejam consideradas as necessidades locais. Esta estratégia pode ser controlada por meio de decisões projetuais simples. Destaca-se que a má orientação dos edifícios em relação aos ventos dominantes pode resultar em desconforto térmico para os usuários. Em estabelecimentos de ensino, o desconforto térmico dificulta o aprendizado e o desenvolvimento das atividades escolares. Além disso, pode acarretar no consumo excessivo de energia elétrica para condicionamento artificial, devido à má adaptação do edifício às condições climáticas locais.

O uso de simulação computacional torna-se uma ferramenta auxiliar na arquitetura, permitindo a análise prévia de fatores que podem interferir na qualidade dos projetos.

A análise do projeto padrão do MEC contribui significativamente para a escolha da orientação mais adequada para a edificação em relação aos ventos dominantes, da localização das aberturas da edificação em projeto, de forma a se obter um adequado fluxo de ar interior e permite estudar adequação de um projeto a ser implantado em todo o Brasil.

Para trabalhos futuros, sugere-se avaliar o efeito na ventilação natural da variação da disposição dos blocos que compõem o projeto.

\section{REFERÊNCIAS}

ALLARD , F. ; GHIAUS , C. ; MANSOURI , Y.. Natural ventilation for health, comfort and energy efficiency . ENCONTRO NACIONAL SOBRE CONFORTO NO AMBIENTE CONSTRUÍDO, 7, CONFERÊNCIA LATINO-AMERICANA SOBRE CONFORTO E DESEMPENHO ENERGÉTICO DE EDIFICAÇÕES, 3, 2003, CURITIBA. ARTIGO TÉCNICO, 2003, Curitiba PR. Anais... 2003.

CÂNDIDO, Christhina. Ventilação natural e códigos de obras: uma análise das tipologias de aberturas nos edifícios de escritórios em Maceió-AL. Dissertação (Mestrado em Arquitetura - Dinâmicas do Espaço Habitado) Universidade Federal de Alagoas, Maceió, Alagoas, 2006.

CHAM. PHOENICS VR 3.6.1. 2005. 1 CD-ROM.

BITTENCOURT, L. S.; CÂNDIDO, C. M. Introdução à ventilação natural. 3. ed. Maceió: EDUFAL, 2008.

FROTA, A. B.; SCHIFFER, S. R. Manual de Conforto Térmico. 6. ed. São Paulo: Studio Nobel, 2003.

LABEEE et al. Arquivos climáticos. UFSC. Disponível em: <http://www.labeee.ufsc.br/downloads/arquivos-climaticos/formato-try-swera-csv-bin> Acesso em: 01 Mai 2014.

LAMBERTS, R.; DUTRA, L. e PEREIRA, F. O. R. Eficiência Energética na Arquitetura. 2. ed. rev. São Paulo: ProLivros, 2004.

MEC. Escola Técnica Padrão. 2011. Programa Brasil Profissionalizado. Disponível em: $<$ http://portal.mec.gov.br/index.php?option=com_content\&view=article\&id=16355\&Itemid=10 11> Acesso em: 01 Mai 2014. 